\title{
Depression Among Keratoconus Patients in Saudi Arabia
}

\author{
Walaa Al-Dairi ${ }^{1}$, Omar M. AL Sowayigh ${ }^{2}$, Ali A. Al Saeed ${ }^{2}$, Ali Alsaad ${ }^{3}$ \\ 1. Surgery, College of Medicine, King Faisal University, Al-Ahsa, SAU 2. Ophthalmology, College of Medicine, King \\ Faisal University, Al-Ahsa, SAU 3. Psychiatry, College of Medicine, King Faisal University, Al-Ahsa, SAU
}

Corresponding author: Omar M. AL Sowayigh,omar-m-008@hotmail.com

\section{Abstract \\ Background}

Depression is a highly prevalent disorder globally and locally in Saudi Arabia. Individuals with chronic conditions are more liable to develop depression. Keratoconus is a chronic progressive corneal disorder that markedly affects the vision and quality of life, making its sufferers liable to developing depression.

\section{Methods}

This is a descriptive cross-sectional study that was conducted using 9-item Patient Health Questionnaire (PHQ-9) to screen for depression among adults aged between 18 and 60 years old only. The participants in this study are patients who have been previously diagnosed with keratoconus by their ophthalmologists. The structured questionnaire was distributed using Google Forms through various social media platforms. After extracting the data, it was revised, coded and then analyzed using the Statistical Packages for Social Sciences (SPSS), version 21 (IBM Corp., Armonk, NY).

\section{Results}

A total of 330 keratoconus patients living in Saudi Arabia were recruited in this study. The modal age group was 31-40 years old (44.5\%), and the male to female ratio was 3:2. The most frequently reported concurrent eye diseases of the patients were astigmatism (48.5\%) and myopia (36.7\%). The prevalence of depression among patients with keratoconus was $40.6 \%(n=134)$. The use of corrective contact lens (includes both: hybrid and rigid lens) in both eyes contributed to a significantly higher depression rate among its wearers compared to users in one eye and non-users $(\mathrm{p}<0.001)$.

\section{Conclusion}

Depression is highly prevalent among keratoconus patients. This is especially true among corrective contact lens wearers of both eyes. Keratoconus is associated with depression regardless of disease severity and socio-demographic characteristics.

Review began 11/09/2020 Review ended 11/29/2020 Published 12/06/2020

\section{() Copyright 2020}

Al-Dairi et al. This is an open access article distributed under the terms of the Creative Commons Attribution License CC-BY 4.0., which permits unrestricted use, distribution, and reproduction in any medium, provided the original author and source are credited.
Categories: Ophthalmology, Psychiatry

Keywords: depression, keratoconus, 9-item patient health questionnaire (phq-9), corrective contact lens

\section{Introduction}

Keratoconus is a chronic progressive ectatic corneal disorder that is bilateral but usually develops asymmetrically [1]. It is characterized by developing a central cone-shaped bulging of the cornea that is explained by its underlying pathophysiology of stromal thinning [2]. The disease starts to develop relatively early in life, becoming especially apparent and symptomatic during puberty [3,4], progressing further and does not stabilize until the thirties of age [4]. Patients often complain of progressive deterioration of vision bilaterally which is attributed to increasing myopia and irregular astigmatism.

The prevalence of keratoconus varies widely in different geographical locations of the world, ranging from 0.3 per 100,000 in Russia to 2,300 per 100,000 in Central India [5,6]. Both genders are affected by keratoconus, however, the literature is divided between which gender is affected more; some showing males to have a higher prevalence [7] and others finding females to be higher [2] while others found no significant differences between the two [3]. In Saudi Arabia, it is more prevalent and found to be more advanced at the time of diagnosis compared to other regions of the world with colder climates and less UV light exposure $[8,9]$. These factors along with eye rubbing $\&$ atopy are well-recognized risk factors, nevertheless, it is believed that the predisposing cause behind it is multifactorial.

Depression is a common, frequently undiagnosed, and serious mental health disorder that is potentially lifethreatening. Along with other mental health disorders, depression poses a great burden on public health worldwide [10]. It is associated with increased disability, morbidity, mortality and suicidal attempts [10,11]. 
It is more likely to affect the elderly and patients with chronic health conditions [12,13]. Additionally, it was found to be more common among females [11], including females in Saudi Arabia [14].

Screening for depression using questionnaires and self-rating scales has been helpful in the primary care settings $[15,16]$. Its use also extends to research purposes in objectively evaluating the possible presence of depression among different studied populations [15,16]. 9-item Patient Health Questionnaire (PHQ-9) and Zung Depression Inventory-Self-Rating Depression Scale (Zung SDS) questionnaires have been used in evaluating depression among keratoconus patients and were found to be both consistent and sensitive [17].

Vision is an extremely valued sense that affects every single detail of our daily life activities, and hence marked deterioration in visual function is related to impairment in one's psychological condition and quality of life $[18,19]$, and therefore it has been linked to depression $[5,17]$. Even though some studies did not demonstrate a relationship between keratoconus and depression [20,21], there is on the other hand supporting evidence that the direct relationship does exist $[5,17]$. By using PHQ-9, we aim in this study to estimate the prevalence of depression among keratoconus patients and explore potential factors implicated in the development of depression among keratoconus patients in Saudi Arabia.

\section{Materials And Methods Study design and participants}

This is a descriptive cross-sectional study that was conducted using PHQ-9 questionnaire to screen for depression. The structured questionnaire was distributed using Google Forms through various social media platforms. The study included adults who were previously diagnosed with keratoconus. All individuals who were younger than 18 or older than 60 were excluded. The data variables that were collected were: age, sex, occupation, province/city, eye conditions, eye procedures and use of corrective eyeglasses or contact lens.

\section{Statistical analysis}

Descriptive statistics were presented using numbers, percentages, mean and standard deviation whenever appropriate. The relationship between the level of depression among the socio-demographic characteristics, other disorders and procedures are done for the patients had been conducted using Chi-square test. P-value of $<0.05$ was considered statistically significant. All statistical data were analyzed using the Statistical Packages for Social Sciences, version 21 (SPSS: IBM Corp., Armonk, NY).

\section{Ethical consideration}

This study was conducted upon the approval of the research ethics committee of the College of Medicine, King Faisal University. All data collected is confidential and a consent was taken from the participants.

\section{Results}

A total of 330 keratoconus patients living in Saudi Arabia were recruited in this study. As seen in Table 1, the modal age group was 31-40 years old (44.5\%). The male to female ratio was 3:2 and were mostly Saudis (88.5\%). Nearly two-thirds (63.6\%) were currently employed. The majority of patients were from the Central region (45.8\%) and the majority were living in a city $(82.4 \%)$. 


\section{Cureus}

Study variables

Age group

$18-30$ years

$31-40$ years

$>40$ years

Gender

Male

Female

Nationality

Saudi

Non-Saudi

Employment status

Unemployed

Employed

Student

Residence region

Central region

Eastern region

Northern region

Southern region

Western region

Residence area

City

Village
N (\%)

$146(44.2 \%)$

147 (44.5\%)

$37(11.2 \%)$

$196(59.4 \%)$

134 (40.6\%)

$292(88.5 \%)$

$38(11.5 \%)$

$86(26.1 \%)$

$210(63.6 \%)$

34 (10.3\%)

151 (45.8\%)

34 (10.3\%)

27 (08.2\%)

$43(13.0 \%)$

75 (22.7\%)

$272(82.4 \%)$

$58(17.6 \%)$

TABLE 1: Socio-demographic characteristics of patients $(n=330)$

Table 2 shows the other eye disorders and the treatment done on the patients. It was revealed that the most frequently reported concurrent eye diseases of the patients were astigmatism (48.5\%) and myopia (36.7\%). We also found that $60.9 \%$ of the patients were using corrective eyeglasses. The proportion of patients who were using a corrective contact lens, who underwent corneal transplantation and post lens implantation in both eyes were $56.7 \%, 5.5 \%$ and $1.8 \%$, respectively. In addition, there were $47.6 \%$ of patients who underwent other eye procedures. 


\section{Cureus}

Parameters

Other eye disorders

Astigmatism

Myopia

Hyperopia

Amblyopia

Other

Use of corrective eyeglasses

Yes

№

Use of corrective contact lens

Single eye

Both eyes

No

Corneal transplantation

Single eye

Both eyes

No

Post lens implantation

Single eye

Both eyes

No

Other eye procedures

Yes

№
N (\%)

160 (48.5\%)

121 (36.7\%)

21 (06.4\%)

$23(07.0 \%)$

$03(01.4 \%)$

201 (60.9\%)

129 (39.1\%)

$67(20.3 \%)$

187 (56.7\%)

76 (23.0\%)

52 (15.8\%)

18 (05.5\%)

260 (78.8\%)

10 (03.0\%)

$06(01.8 \%)$

314 (95.2\%)

$157(47.6 \%)$

$173(52.4 \%)$

TABLE 2: Patients' other eye disorders and procedures $(n=330)$

Figure 1 depicts the other eye procedures performed on the patients. It shows that crosslinking was the most common procedure performed on the patients (69.4\%), followed by photorefractive keratectomy (PRK) $(17.2 \%)$ and intrastromal corneal ring (ICR) (11.5\%). 


\section{Cureus}

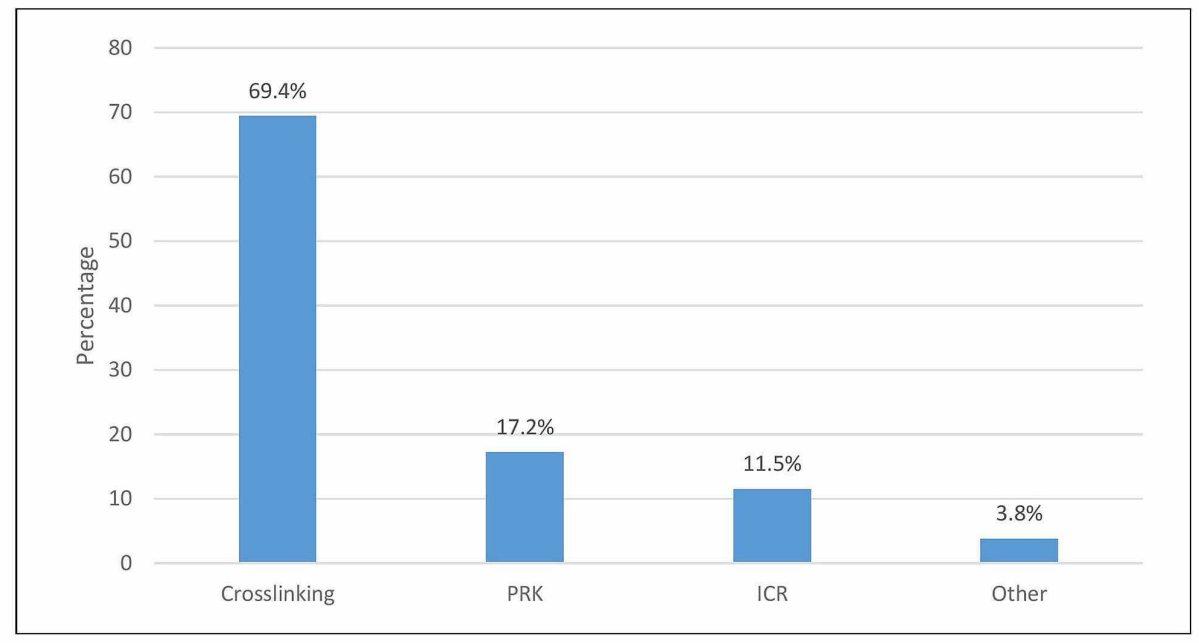

\section{FIGURE 1: Specific other eye procedures}

PRK, photorefractive keratectomy; ICR, intrastromal corneal ring.

Table 3 shows the grades of depression. The prevalence of depression among patients with keratoconus was 40.6\% while 59.4\% were not depressed (mean score: $9.26 \pm 5.81$ SD, 95\% CI: 8.26-9.89).

\begin{tabular}{|l|l|}
\hline Variables & N (\%) \\
\hline Total depression score (mean \pm SD, 95\% Cl) & $9.26 \pm 5.81,8.26-9.89$ \\
\hline Level of depression & $134(40.6 \%)$ \\
\hline Depressed & $196(59.4 \%)$ \\
\hline Not depressed & \\
\hline Depression severity $(n=134)$ & $17(12.7 \%)$ \\
\hline Mild depression & $63(47.0 \%)$ \\
Moderate depression & $36(26.9 \%)$ \\
\hline Moderately severe depression & $18(13.4 \%)$
\end{tabular}

\section{TABLE 3: Prevalence of depression using PHQ-9 $(n=330)$}

SD: standard deviation, Cl: confidence interval, PHQ-9: 9-item Patient Health Questionnaire.

When measuring the severity level, moderate depression was found among $47 \%$, followed by moderately severe (26.9\%), while severe depression was found among 13.4\% (Figure 2). 


\section{Cureus}

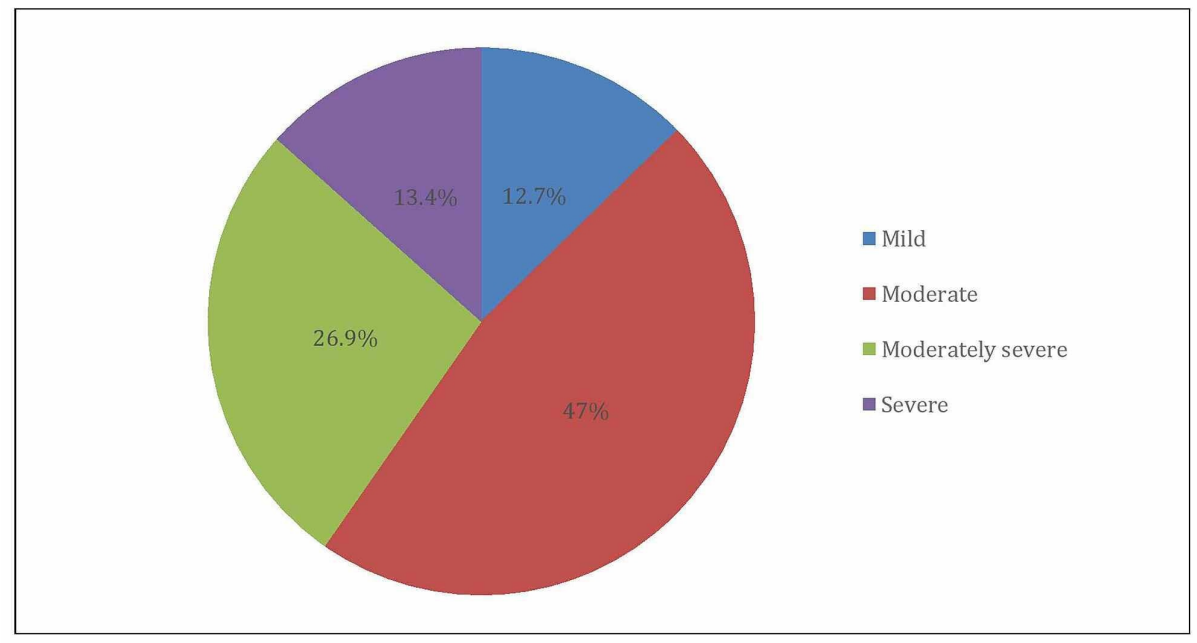

FIGURE 2: Severity of depression

When measuring the relationship between the level of depression and the socio-demographic characteristics of the patients, it was found that Saudis were significantly more depressed compared to non-Saudis $\left(\mathrm{X}^{2}=\right.$ 7.066; $\mathrm{p}=0.008$ ). No other socio-demographic variables showed a significant relationship with depression other than nationality since; age group, gender, employment status, residence region and residence area did not show a significant relationship when compared to depression (all p >0.05) (Table 4). 


\section{Cureus}

\begin{tabular}{|c|c|c|c|c|}
\hline \multirow{2}{*}{ Factor } & \multicolumn{2}{|l|}{ Level of depression } & \multirow{2}{*}{$x^{2}$} & \multirow{2}{*}{ p-value ${ }^{s}$} \\
\hline & Depressed N $(\%)^{(n=134)}$ & Not Depressed $N(\%)(n=196)$ & & \\
\hline \multicolumn{5}{|l|}{ Age group } \\
\hline $18-30$ years & $59(44.0 \%)$ & $87(44.0 \%)$ & \multirow{3}{*}{0.612} & \multirow{3}{*}{0.736} \\
\hline 31 - 40 years & $62(46.3 \%)$ & $85(43.4 \%)$ & & \\
\hline$>40$ years & $13(09.7 \%)$ & $24(12.2 \%)$ & & \\
\hline \multicolumn{5}{|l|}{ Gender } \\
\hline Male & $80(59.7 \%)$ & $116(59.2 \%)$ & \multirow{2}{*}{0.009} & \multirow{2}{*}{0.925} \\
\hline Female & $54(40.3 \%)$ & $80(40.8 \%)$ & & \\
\hline \multicolumn{5}{|l|}{ Nationality } \\
\hline Saudi & $111(82.8 \%)$ & $181(92.3 \%)$ & \multirow{2}{*}{7.066} & \multirow[b]{2}{*}{$0.008 *$} \\
\hline Non-Saudi & $23(17.2 \%)$ & $15(07.7 \%)$ & & \\
\hline \multicolumn{5}{|c|}{ Employment status } \\
\hline Unemployed & $39(29.1 \%)$ & $47(24.0 \%)$ & \multirow{3}{*}{1.525} & \multirow{3}{*}{0.467} \\
\hline Employed & $80(59.7 \%)$ & $130(56.3 \%)$ & & \\
\hline Student & $15(11.2 \%)$ & $19(09.7 \%)$ & & \\
\hline \multicolumn{5}{|l|}{ Residence region } \\
\hline Central region & $66(49.3 \%)$ & $85(43.4 \%)$ & \multirow{5}{*}{2.191} & \multirow{5}{*}{0.701} \\
\hline Eastem region & $15(11.2 \%)$ & $19(09.7 \%)$ & & \\
\hline Northern region & $10(07.5 \%)$ & $17(08.7 \%)$ & & \\
\hline Southem region & $14(10.4 \%)$ & $29(14.8 \%)$ & & \\
\hline Western region & $29(21.6 \%)$ & $46(23.5 \%)$ & & \\
\hline \multicolumn{5}{|l|}{ Residence area } \\
\hline city & $111(82.8 \%)$ & $161(82.1 \%)$ & \multirow{2}{*}{0.026} & \multirow{2}{*}{0.871} \\
\hline Village & $23(17.2 \%)$ & 35 (17.9\%) & & \\
\hline
\end{tabular}

TABLE 4: Relationship between the level of depression and socio-demographic characteristics of patients $(n=330)$

$\S p$-value has been calculated using the chi-square test. ${ }^{*}$ Significant at $\mathrm{p}<0.05$ level.

When measuring the relationship between the level of depression among other eye disorders and treatment of the patients, it was found that only the use of corrective contact lens (includes both: hybrid and rigid lens) showed significant association with depression where the use of corrective contact lens in both eyes exhibited higher depression rate compared to the other groups $\left(X^{2}=17.084 ; \mathrm{p}<0.001\right)$. Other variables included in the table showed no significant relationship with depression (all $p>0.05$ ) (Table 5). 


\section{Cureus}

\begin{tabular}{|c|c|c|c|c|}
\hline \multirow{2}{*}{ Factor } & \multicolumn{2}{|l|}{ Level of depression } & \multirow{2}{*}{$x^{2}$} & \multirow{2}{*}{ p-value $s$} \\
\hline & Depressed $N(\%)^{(n=134)}$ & Not Depressed N $(\%)^{(n=196)}$ & & \\
\hline \multicolumn{5}{|c|}{ Other eye diseases * } \\
\hline Astigmatism & $72(53.7 \%)$ & $88(44.9 \%)$ & 2.486 & 0.115 \\
\hline Myopia & $50(37.3 \%)$ & $71(36.2 \%)$ & 0.041 & 0.840 \\
\hline Hyperopia & $09(06.7 \%)$ & $12(06.1 \%)$ & 0.047 & 0.828 \\
\hline Amblyopia & $10(07.5 \%)$ & $13(06.6 \%)$ & 0.085 & 0.771 \\
\hline other & $02(01.5 \%)$ & $01(0.50 \%)$ & 0.853 & 0.356 \\
\hline \multicolumn{5}{|c|}{ Use of corrective eyeglasses } \\
\hline Yes & $80(59.7 \%)$ & $121(61.7 \%)$ & \multirow{2}{*}{0.138} & \multirow{2}{*}{0.710} \\
\hline No & $54(40.3 \%)$ & $75(38.3 \%)$ & & \\
\hline \multicolumn{5}{|c|}{ Use of corrective contact lens } \\
\hline Single eye & $27(20.1 \%)$ & $40(20.4 \%)$ & \multirow{3}{*}{17.084} & \multirow{3}{*}{$<0.001 *$} \\
\hline Both eyes & $91(67.9 \%)$ & $96(49.0 \%)$ & & \\
\hline № & $16(11.9 \%)$ & $60(30.6 \%)$ & & \\
\hline \multicolumn{5}{|c|}{ Corneal transplantation } \\
\hline Single eye & $17(12.7 \%)$ & $35(17.9 \%)$ & \multirow{3}{*}{2.103} & \multirow{3}{*}{0.349} \\
\hline Both eyes & $09(06.7 \%)$ & $09(04.6 \%)$ & & \\
\hline № & $108(80.6 \%)$ & $152(77.6 \%)$ & & \\
\hline \multicolumn{5}{|c|}{ Post lens implantation } \\
\hline Single eye & $06(04.5 \%)$ & $04(02.0 \%)$ & \multirow{3}{*}{1.721} & \multirow{3}{*}{0.423} \\
\hline Both eyes & $02(01.5 \%)$ & $04(02.0 \%)$ & & \\
\hline № & $126(94.0 \%)$ & $188(95.9 \%)$ & & \\
\hline \multicolumn{5}{|c|}{ Other eye procedures } \\
\hline Yes & $68(50.7 \%)$ & $89(45.4 \%)$ & \multirow{2}{*}{0.909} & \multirow{2}{*}{0.340} \\
\hline № & $66(49.3 \%)$ & $107(54.6 \%)$ & & \\
\hline \multicolumn{5}{|c|}{ Specific other eye procedures * } \\
\hline Crosslinking & $47(69.1 \%)$ & $62(69.7 \%)$ & 0.005 & 0.941 \\
\hline ICR & $04(05.9 \%)$ & $14(15.7 \%)$ & 3.683 & 0.055 \\
\hline PRK & $15(22.1 \%)$ & $12(13.5 \%)$ & 1.991 & 0.158 \\
\hline Other & $03(04.4 \%)$ & $03(03.4 \%)$ & 0.114 & 0.736 \\
\hline
\end{tabular}

TABLE 5: Relationship between the level of depression among the patients' other eye disorders and procedures $(n=330)$

*Variable with multiple responses. §p-value has been calculated using the chi-square test. **Significant at $p<0.05$ level. PRK, photorefractive keratectomy; ICR, intrastromal corneal ring.

\section{Discussion}

To our knowledge, this is the first study to evaluate and estimate the prevalence of depression among keratoconus patients in Saudi Arabia and the Middle East. By using PHQ-9, we found that the prevalence of 
depression among previously diagnosed keratoconus patients is $40.6 \%$ in various degrees of severity. This is a very high percentage considering not all participants may be having severe keratoconus. This signifies the role of keratoconus in developing depression regardless of the severity or impact on visual impairment as was found in Moschos's study [17].

When compared to other chronic conditions, the depression prevalence among keratoconus patients in Saudi Arabia is at the middle ground between higher depression rates of sickle cell anemia (48.2\%-85.9\%) [22,23] and chronic pain (71\%) [24] and lower depression rates of chronic kidney disease (6.8\%-24.6\%) $[25,26]$ and type 2 diabetes mellitus (33.8\%) [27].

Other than nationality, the socio-demographic characteristics didn't seem to be associated with depression. Even though Saudis were significantly more depressed statistically compared to non-Saudis, we believe that the association isn't clinically significant. A bigger sample of non-Saudis is needed for comparison to prove such an association. Further exploration of the role of ethnicity/nationality in depression among keratoconus patients is needed as this is beyond the scope of this study.

Even though depression is more common among females [11,14], we did not find a significant relationship between depression among keratoconus patients and gender. This may indicate that keratoconus is associated with depression regardless of the gender. In contrast, in Chen et al.'s study of depression among glaucoma patients; females, older patients and lower-income individuals were at a greater risk of developing depression [28].

Having a concurrent eye disease such as astigmatism, myopia, hyperopia and amblyopia isn't significantly related to developing depression even though it has been reported that myopia and amblyopia are related to the development of depression [29,30].

The use of corrective contact lens in both eyes is associated with a significantly higher depression rate among keratoconus patients. This may be attributed to the extra amount of effort required to cope with them and their impact on daily life activities when compared to other minor daily hindrances such as corrective eyeglasses or the almost nonexistent hindrance of corneal transplantation, post-lens implantation and other eye procedures. Of course, the visual function among keratoconus patients is not identical across the different conducted eye procedures, and so it is difficult to attribute a certain eye procedure with being depressed or not. Additionally, in Saudi Arabia, the expenses of corrective contact and non-contact lens aren't covered by the government or insurance companies which becomes a financial burden for patients with keratoconus.

A limitation of this study was not being able to exclude participants of early keratoconus with good spectacle vision as it was conducted on an online basis rather than in an ophthalmology clinic. Another limitation was the inability to measure the best-corrected distance visual acuity (CDVA). Additionally, there may be other factors associated with developing depression or having a higher depression score than usual in such patients which have not been investigated in this study, these include multiple comorbidities, grief, medications and recent traumatic events.

Further studies are needed to evaluate the factors of good spectacle vision and best CDVA on the development of depression among keratoconus patients. In addition, further exploration of the role of ethnicity/nationality in depression among keratoconus patients is needed.

\section{Conclusions}

Depression is highly prevalent among keratoconus patients. This is especially true among corrective contact lens wearers of both eyes. Keratoconus is associated with depression regardless of disease severity and socio-demographic characteristics. We recommend screening for depression among patients diagnosed with keratoconus in ophthalmology clinics as well as primary care clinics, and to have special care provided for those using corrective contact lens in both eyes. Clinically, when treating keratoconus patients, ophthalmologists and optometrists need to provide psychological support and consider early referral to psychiatrists which could potentially improve the quality of life.

\section{Additional Information}

\section{Disclosures}

Human subjects: Consent was obtained by all participants in this study. Research Ethics Committee, King Faisal University issued approval N/A. This study was conducted upon the approval of the research ethics committee of College of Medicine, King Faisal University. . Animal subjects: All authors have confirmed that this study did not involve animal subjects or tissue. Conflicts of interest: In compliance with the ICMJE uniform disclosure form, all authors declare the following: Payment/services info: All authors have declared that no financial support was received from any organization for the submitted work. Financial relationships: All authors have declared that they have no financial relationships at present or within the previous three years with any organizations that might have an interest in the submitted work. Other 
relationships: All authors have declared that there are no other relationships or activities that could appear to have influenced the submitted work.

\section{References}

1. Zadnik K, Steger-May K, Fink BA, et al.: Between-eye asymmetry in keratoconus . Cornea. 2002, 21:671-679. 10.1097/00003226-200210000-00008

2. Krachmer JH, Feder RS, Belin MW: Keratoconus and related noninflammatory corneal thinning disorders. Surv Ophthalmol. 1984, 28:293-322. 10.1016/0039-6257(84)90094-8

3. Kennedy RH, Bourne WM, Dyer JA: A 48-year clinical and epidemiologic study of keratoconus . Am J Ophthalmol. 1986, 101:267-273. 10.1016/0002-9394(86)90817-2

4. Rabinowitz YS: Keratoconus. Surv Ophthalmol. 1998, 42:297-319. 10.1016/S0039-6257(97)00119-7

5. Gorskova EN, Sevost'ianov EN, Baturin NA: Results of psychological testing of patients with keratoconus . Vestn Oftalmol. 1998, 114:44-45.

6. Jonas JB, Nangia V, Matin A, Kulkarni M, Bhojwani K: Prevalence and Associations of Keratoconus in Rural Maharashtra in Central India: The Central India Eye and Medical Study. Am J Ophthalmol. 2009, 148:760765. 10.1016/j.ajo.2009.06.024

7. Pearson AR, Soneji B, Sarvananthan N, Sanford-Smith JH: Does ethnic origin influence the incidence or severity of keratoconus?. Eye. 2000, 14:625-628. 10.1038/eye.2000.154

8. Assiri AA, Yousuf BI, Quantock AJ, Murphy PJ: Incidence and severity of keratoconus in Asir province, Saudi Arabia. Br J Ophthalmol. 2005, 89:1403-1406. 10.1136/bjo.2005.074955

9. Gokhale NS: Epidemiology of keratoconus. Indian J Ophthalmol. 2013, 61:382-383. 10.4103/03014738.116054

10. World Health Organization. Department of Mental Health and Substance Dependence, Noncommunicable Diseases and Mental Health: Investing in Mental Health. World Health Organization, Geneva; 2003.

11. Abate KH: Gender disparity in prevalence of depression among patient population: a systematic review . Ethiop J Health Sci. 2013, 23:283-288. 10.4314/ejhs.v23i3.11

12. Wilhelm K, Mitchell P, Slade T, Brownhill S, Andrews G: Prevalence and correlates of DSM-IV major depression in an Australian national survey. J Affect Disord. 2003, 75:155-162. 10.1016/S01650327(02)00040-X

13. Mitchell AJ, Chan M, Bhatti H, et al.: Prevalence of depression, anxiety, and adjustment disorder in oncological, haematological, and palliative-care settings: a meta-analysis of 94 interview-based studies. Lancet Oncol. 2011, 12:160-174. 10.1016/S1470-2045(11)70002-X

14. Al-Qadhi W, ur Rahman S, Ferwana MS, Abdulmajeed IA: Adult depression screening in Saudi primary care: prevalence, instrument and cost. BMC Psychiatry. 2014, 14:190. 10.1186/1471-244X-14-190

15. Kroenke K, Spitzer RL, Williams JBW: The PHQ- 9: validity of a brief depression severity measure . J Gen Intern Med. 2001, 16:606-613. 10.1046/j.1525-1497.2001.016009606.x

16. Zung WW: A self-rating depression scale. Arch Gen Psychiatry. 1965, 12:63-70. 10.1007/978-94-007-0753$5 \_104628$

17. Moschos MM, Gouliopoulos NS, Kalogeropoulos C, et al.: Psychological aspects and depression in patients with symptomatic keratoconus. J Ophthalmol. 2018, 2018:7314308. 10.1155/2018/7314308

18. Huang CQ, Dong BR, Lu ZC, Yue JR, Liu QX: Chronic diseases and risk for depression in old age: a metaanalysis of published literature. Ageing Res Rev. 2010, 9:131-141. 10.1016/j.arr.2009.05.005

19. Moreira LB, Alchieri JC, Belfort R, Moreira H: Psychological and social aspects of patients with keratoconus . Arq Bras Oftalmol. 2007, 70:317-322. 10.1590/s0004-27492007000200023

20. Woodward MA, Blachley TS, Stein JD: The association between sociodemographic factors, common systemic diseases, and keratoconus an analysis of a nationwide heath care claims database. Ophthalmology. 2016, 123:457-465. 10.1016/j.ophtha.2015.10.035

21. Jonas JB, Wei W Bin, Xu L, Rietschel M, Streit F, Wang YX: Self-rated depression and eye diseases: The Beijing Eye Study. PLoS One. 2018, 13:e0202132. 10.1371/journal.pone.0202132

22. Alhomoud MA, Gosadi IM, Wahbi HA: Depression among sickle cell anemia patients in the eastern province of Saudi Arabia. Saudi J Med Med Sci. 2018, 6:8-12. 10.4103/sjmms.sjmms_123_16

23. Alsubaie SS, Almathami MA, Abouelyazid A, Alqahtani MM: Prevalence of depression among adults with sickle cell disease in the southern region of Saudi Arabia. Pakistan J Med Sci. 2018, 34:929-933. 10.12669/pjms.344.14760

24. Al-Maharbi S, Abolkhair A, Al Ghamdi H, et al.: Prevalence of depression and its association with sociodemographic factors in patients with chronic pain: a cross-sectional study in a tertiary care hospital in Saudi Arabia. Saudi J Anaesth. 2018, 12:419-425. 10.4103/sja.SJA_771_17

25. Al Zaben F, Khalifa DA, Sehlo MG, et al.: Depression in patients with chronic kidney disease on dialysis in Saudi Arabia. Int Urol Nephrol. 2014, 46:2393-2402. 10.1007/s11255-014-0802-2

26. Mosleh H, Alenezi M, Al johani S, Alsani A, Fairaq G, Bedaiwi R: Prevalence and factors of anxiety and depression in chronic kidney disease patients undergoing hemodialysis: a cross-sectional single-center study in Saudi Arabia. Cureus. 2020, 12:e6668. 10.7759/cureus.6668

27. Alzahrani A, Alghamdi A, Alqarni T, Alshareef R, Alzahrani A: Prevalence and predictors of depression, anxiety, and stress symptoms among patients with type II diabetes attending primary healthcare centers in the western region of Saudi Arabia: a cross-sectional study. Int J Ment Health Syst. 2019, 13:48. 10.1186/s13033-019-0307-6

28. Chen YY, Lai YJ, Wang JP, et al.: The association between glaucoma and risk of depression: a nationwide population-based cohort study. BMC Ophthalmol. 2018, 18:146. 10.1186/s12886-018-0811-5

29. Packwood EA, Cruz OA, Rychwalski PJ, Keech RV: The psychosocial effects of amblyopia study . J AAPOS. 1999, 3:15-17. 10.1016/S1091-8531(99)70089-3

30. Wu Y, Ma Q, Sun HP, Xu Y, Niu ME, Pan CW: Myopia and depressive symptoms among older Chinese adults. PLoS One. 2017, 12:e0177613. 10.1371/journal.pone.0177613 